\title{
Towards More Balanced Territorial Relations-The Role (and Limitations) of Spatial Planning as a Governance Approach
}

\author{
Karlheinz Knickel ${ }^{1, *}{ }^{\infty}$, Alexandra Almeida ${ }^{2}$, Lisa Bauchinger ${ }^{3}{ }^{-}$, Maria Pia Casini ${ }^{4}$, Bernd Gassler ${ }^{5}$, \\ Kerstin Hausegger-Nestelberger ${ }^{5}$, Jesse Heley ${ }^{6}\left(\mathbb{D}\right.$, Reinhard Henke ${ }^{7}\left({ }^{\circ}\right.$, Marina Knickel ${ }^{8}{ }^{(}$, Henk Oostindie ${ }^{9}$, \\ Ulla Ovaska ${ }^{10} \mathbb{D}$, Carlos Pina ${ }^{2} \mathbb{D}$, Massimo Rovai ${ }^{8} \mathbb{D}$, Hans Vulto ${ }^{11}$ and Johannes S. C. Wiskerke ${ }^{9, *} \mathbb{C}$
}

Citation: Knickel, K.; Almeida, A.; Bauchinger, L.; Casini, M.P.; Gassler, B.; Hausegger-Nestelberger, K.; Heley, J.; Henke, R.; Knickel, M.; Oostindie, H.; et al. Towards More Balanced Territorial Relations-The Role (and Limitations) of Spatial Planning as a Governance Approach. Sustainability 2021, 13, 5308. https://doi.org/ $10.3390 /$ su13095308

Academic Editors: Eduardo José Rocha Medeiros and Jacek Zaucha

Received: 5 April 2021

Accepted: 5 May 2021

Published: 10 May 2021

Publisher's Note: MDPI stays neutral with regard to jurisdictional claims in published maps and institutional affiliations.

Copyright: (c) 2021 by the authors. Licensee MDPI, Basel, Switzerland. This article is an open access article distributed under the terms and conditions of the Creative Commons Attribution (CC BY) license (https:/ / creativecommons.org/licenses/by/ $4.0 /)$.
1 HELSUS-Helsinki Institute of Sustainability Science, Department of Economics and Management, Faculty of Agriculture and Forestry, University of Helsinki, FI-00014 Helsinki, Finland

2 Comissão de Coordenação e Desenvolvimento Regional de Lisboa e Vale do Tejo (CCDR-LVT), 1269-053 Lisboa, Portugal; alexandra.almeida@ccdr-lvt.pt (A.A.); carlos.pina@ccdr-lvt.pt (C.P.)

3 Federal Institute for Agricultural Economics, Rural and Mountain Research, A-1030 Vienna, Austria; lisa.bauchinger@bab.gv.at

4 Territorial Planning Office, Province of Lucca, 55100 Lucca, Italy; m.casini@provincia.lucca.it

5 Regional Management of Metropolitan Area of Styria, A-8010 Graz, Austria; gassler@zentralraum-stmk.at (B.G.); hausegger-nestelberger@zentralraum-stmk.at (K.H.-N.)

6 Research Group 'New Political Geographies', Department of Geography and Earth Sciences, Aberystwyth University, Aberystwyth SY23 3DB, UK; eyh@aber.ac.uk

7 Regionalverband FrankfurtRheinMain, D-60329 Frankfurt am Main, Germany; Henke@region-frankfurt.de

8 Department of Agriculture, Food and Environment (DAFE), Pisa University, I-56124 Pisa, Italy; marina.kobzeva@phd.unipi.it (M.K.); massimo.rovai@unipi.it (M.R.)

9 Rural Sociology Group (RSO), Section Space, Place and Society (SPS), Wageningen University, NL-6700 HB Wageningen, The Netherlands; henk.oostindie@wur.nl

10 Rural Studies, Land Use and Natural Resource Governance Group, Natural Resources Institute Finland (LUKE), FI-00790 Helsinki, Finland; ulla.ovaska@luke.fi

11 Municipality of Ede, NL-6877 Ede, The Netherlands; hans.vulto@ede.nl

* Correspondence: karlheinz.knickel@helsinki.fi (K.K.); han.wiskerke@wur.nl (J.S.C.W.); Tel.: +49-152-2388-9339 (K.K.)

Abstract: Decision-makers, planners and administrators involved in different policy domains at different governance levels face the important challenge of fostering more balanced, sustainable and territorially integrated development. Well-designed, multi-level, multi-sector and multi-actor governance arrangements can play a key role in this process through orchestrating the interplay between different spheres, activities, actors and interests. In this paper, we examine the role of spatial planning in improving the relations between rural, peri-urban and urban areas. We analyse the strengths and limitations of spatial planning and explore the connections with territorial development. The methodology used for this analysis combines regional case studies in seven European locations-Ede, Frankfurt/Rhein-Main, Styria/Graz, Helsinki, Lisbon, Lucca and Mid Wales, with rapid appraisals, the analysis of published data, expert judgement and triangulation. We ask under which conditions spatial planning can induce more balanced, sustainable territorial relations, and look at the contribution planning can make to achieving sustainable development goals. The problem of ineffective (or toothless) plan implementation provides the entry point into the analysis and discussion. We illustrate why mutually beneficial relations between urban, peri-urban and rural communities (and territories) cannot simply be planned. Instead, these relationships need to be supported by strategies, policy instruments and governance arrangements that foster synergies between different actors and activities. The planning process itself needs to become more transparent and participatory. We conclude that the questions addressed in this article in an exploratory fashion merit further research especially as a more sustainable and territorially integrated development is becoming increasingly important in European policy making.

Keywords: urban; peri-urban; rural; spatial planning; territorial governance; sustainable development; case studies; Europe 


\section{Introduction}

\subsection{Towards a More Balanced, Sustainable and Territorially Integrated Development}

Territorial development is commonly referred to as "integrated multi-sector development across a specific portion of territory, guided by a spatial vision of the desirable future and supported by strategic investments in physical infrastructure and environmental management" [1] (p. 15). Territorial development can also be used as an umbrella term for "development of specific (typically sub-national) portions of territory. These may be an urban, metropolitan, regional or rural jurisdiction, but also watershed, coastal, mountainous, border areas, etc." [1] (p. 16). Following this definition, we can see the relations between urban, peri-urban and rural areas as territorial relations. Whenever it is about improved relations, in this article, we speak about territorial development with a positive connotation.

Governance arrangements play a central role in achieving territorial development goals [2]. If well-designed, they can effectively orchestrate the interplay between different sectors, actors and interests. Coordination across multi-level governance systems and the management of the interests of different sectors and actors play a critical role in harmonising economic development, social inclusion and environmental protection. The related challenge for decision-makers, developers, planners and administrators involved at different governance levels and in different policy domains is to combine the use of different instruments in a way that fosters a more balanced and territorially integrated development.

In this article we examine the role of planning in this orchestration, and specifically in fostering beneficial relations between rural, peri-urban and urban areas. When referring to planning, we recognise that there are different types of planning, and that there are different interpretations in different countries [3,4]. Table 1 provides an indicative differentiation of various types of (spatial) planning based on main goals and focus.

Table 1. The main goal and focus of different types of (spatial) planning *.

\begin{tabular}{cc}
\hline Type & Main Goal \\
\hline Spatial planning & $\begin{array}{c}\text { Mediating between the respective claims on space of the state, market } \\
\text { and community; coordinating practices and policies affecting spatial } \\
\text { organisation. }\end{array}$ \\
\hline Territorial planning & $\begin{array}{c}\text { Realising economic, social, cultural and environmental goals through the } \\
\text { development of spatial visions, strategies and plans, as well as the } \\
\text { application of policy tools, institutional and participatory mechanisms } \\
\text { and regulatory procedures. }\end{array}$ \\
\hline Regional planning & $\begin{array}{c}\text { Addressing region-wide economic, social and environmental issues, } \\
\text { including efficient placement of infrastructure, settlements, industrial } \\
\text { spaces and nature reserves. }\end{array}$ \\
\hline Land use planning & $\begin{array}{c}\text { Ordering and regulating the use of land to mitigate land use conflicts, } \\
\text { foster environmental conservation, limit urban sprawl and minimise } \\
\text { transport costs. }\end{array}$ \\
\hline
\end{tabular}

Source: Authors' compilation based on [3,4]. * Other variants include urban, rural, environmental and economic planning, strategic spatial planning, integrated development and community planning.

These different forms of planning play different roles in shaping territorial relationships. Regional and land use planning can be seen as discrete professional disciplines of spatial planning. Territorial planning tends to go beyond in integrating sectoral policies and promoting development projects, as well as integrating stakeholder involvement. Important in practical terms is that spatial planning usually has a precise mandate and must follow a specific process.

With this in mind, we refer to planning, irrespective of whether in the original sources more specific terms are used. Where a specific type of planning is under direct consideration, we are more precise in our discussion of this example. At the same time, we pay attention to the fact that different forms of planning mean different things in different coun- 
tries. For the analysis, we define planning as the process of thinking about, and designing, organising, combining or locating the activities required to achieve a desired goal.

\subsection{Recent Research on the Role of Spatial Planning in Determining Territorial Relations}

Related to the question how spatial planning, planning governance and complementary territorial governance arrangements can contribute to more beneficial territorial relations, we focus our brief review of recent research on the following issues:

- The increasing importance of more distributed and collaborative models of planning and decision-making, and what this means for the impact of spatial planning on territorial relations.

- The role of civic engagement in planning, the ways it is achieved and its impact on the quality of planning processes.

- The trend towards peri-urbanisation, which involves issues of land use planning, landscape management, conservation, infrastructure provision and social exclusion.

- The increasing importance of development concepts that aim at orienting regional resources towards the competitive strengths and goals of a region.

- The move from the functional segregation of rural and urban space, and land uses, towards more integrated perspectives and towards planning rural and urban areas together.

Shucksmith (2010) points out that in contemporary spatial planning a "top-down approach to government intervention and direction" is emphasised [5] (p. 5). He continues, stating that recent decades have witnessed a shift from the centralised state towards more collaborative models of organisation, planning and decision-making. Naldi et al. (2015) add that spatial planning must not mean the imposing of regional strategies by means of top-down regional or governmental planning processes [6]. Related to the shift towards more collaborative models, we can also see that the boundaries between public and private sectors are not so clear anymore $[5,6]$. Overall, a shift from government to governance can be observed, and the role of the state is coordinating and enabling rather than providing or directing. A sometimes overlooked aspect of this is that decentralised and local steering can, as some of our examples show, also provide a bigger scope for sustainable economies, thereby counterbalancing globalisation impacts.

The German Council for Sustainable Development (Nachhaltigkeitsrat, 2005) was one of the first to note that the State can only tackle key future issues by engaging in dialogue with citizens and those participating in economy and in society [7]. Fürst (2001), Knickel (2005) and others emphasise that the increasing attention paid to the (micro-)regional and local level in policy fine-tuning and implementation are also a response to the increasing awareness that many questions can no longer be dealt with efficiently in a top-down manner $[8,9]$. Civic engagement plays an increasingly important role in more collaborative models of organisation, planning and decision-making. The ways civic engagement is achieved range from involving the public in initial (scoping) and later stages of planning processes to more far-reaching citizen participation and collaborative planning [3,10]. In some kinds of planning, citizens—not planners or politicians—-take the driving seat [10].

Research on peri-urban areas has often seen peri-urbanisation as a spatial planning problem, involving issues of spatial planning, development control, conservation and ecosystem protection, infrastructure provision and social exclusion [11,12]. Briquel and Collicard (2005) add that planners need to recognise the diversity of peri-urban areas [13]. Particularly relevant for transitional areas is the development of more strategic spatial planning [11]. Strategic spatial planning has a long-term vision and adopts a panoptic view sitting above local government territories. It goes beyond land use planning by also considering economic development, transport, service provision, ecosystem services and the connections across sectors [11-14].

Development concepts that prioritise an enhanced utilisation of the competitive strengths of a region [6] have been rather dominant in recent years in EU-level discourses and policy development. Smart development, smart specialisation and smart growth are 
variants of this basic idea. We argue later that single developmental models hardly ever make sense in the different historical, institutional, socio-economic and cultural settings across Europe. It is therefore much more meaningful if such concepts foster bottom-up planning processes aimed at orienting regional resources and development. The basic idea then is to work with the capabilities and potentials of certain spaces or territories, considering their diversity in terms of economic conditions, knowledge, and innovation capacity [6]. The Joint Research Centre's smart specialisation platform, in line with that, champions a bottom-up strategic approach that begins with bringing stakeholders together to define regional priorities [15].

Keeping these broader shifts towards collaborative governance and orienting regional resources towards the competitive strengths of a region in mind, we also explored what this might mean for the planning of territorial relations. Generally, we found many examples of a functional segregation or compartmentalisation of urban and rural land uses. Examples from the UK, Netherlands and Germany illustrate this:

- The Town and Country Planning Act 1947 in the UK provides an example of a system of development control designed to enforce the separation of rural and urban space [16]. Boelens (2011) and Busck et al. (2009) found similar patterns in the Netherlands, where functional segregation and spatial quality have informed the strict compartmentalisation of urban and rural land uses. Connected, the rural character of territories is protected through restricted development. Building is only allowed with planning permission, and planning permission is only granted if the municipal plan has designated a place as apt for (a specific type of) buildings [17,18].

- In the UK and in Germany, green belts have historically succeeded in tightly constraining the built-up areas of major cities. Murdoch and Marsden (1994) argue that green belts have also in effect produced a displaced suburbanisation, with out-migrants from cities "leapfrogging" protected areas and driving settlement growth and housing development in rural areas beyond the greenbelt [19]. Gallent et al. (2008) suggest that new settlements were directed to the rural-urban fringe, not because of proactive spatial planning, but because the transitional zone of the fringe was the least contentious [20]. The same authors add that a closely related instrument is the drawing of development envelopes around smaller towns and villages.

At the same time there are many analysts who emphasise that spatial planning needs to plan rural and urban areas together [12,13,21,22]. Gallent et al. (2008) point out that, since 1999, the European Spatial Development Perspective (ESDP) has been paying particular attention to "the need for a new urban-rural relationship, as a means of overcoming the dualism between city and countryside and as an essential prerequisite to achieving territorial cohesion" [20] (p. 294). Brown and Shucksmith (2017) go beyond, arguing that this provides an opportunity to address mismatches between administrative and functional areas, and for integrating different sectors such as transport, infrastructure and education [23]. Related examples are:

- The city-countryside partnerships in Germany aimed at enabling urban and rural areas to take over responsibility for larger territories [24]. Projects were to benefit the entire territory through development across rural-urban divides. The basic idea was that growth and innovation can be promoted regionally in a better way when the potentials of urban and rural areas are combined, and when these are not treated as separate spheres. An associated aim was to promote sustainable development of larger city-regions through an improved and jointly coordinated decision-strategy between public and private actors [25].

- The Wales Spatial Plan (WSP), produced in 2004, is an example of planning rural and urban areas together [26]. The WSP articulated a national spatial planning vision for Wales that is based on six functional regions encompassing both rural and urban localities, differentiated by fuzzy boundaries. The approach has its limitations, as emphasised by Heley (2013), who argues that the WSP has impacted the consciousness 
and networks of policy makers and political actors, while its ability to shape and instigate change "on the ground" has been limited [27].

On the basis of this brief review of recent research, we can summarise that, overall, a shift towards a more holistic view of territories in spatial planning and programming is recognised and seen as desirable. Romeo (2015) emphasises that the operationalisation of such an approach is not straightforward, and that many advocates of a spatially integrated development may underestimate the complex operation of economic and social sectors across multiple scales. He adds that integration across sectors might exceed the coordination capacity of local authorities [1].

In line with the results of our review, we pay in our empirical analysis particular attention to the connections between a more balanced territorial development, the planning process as such, and the role of civic engagement in this process. Other aspects that we look out for include the key features of more distributed and collaborative models of planning and decision-making, and the mechanisms, territorial governance processes and instruments that are linked with plan implementation.

\subsection{Key Questions Addressed in This Article}

The overarching question we ask in this article is if and how more beneficial territorial relations can be planned, and what complementary territorial governance arrangements are needed. Attention in the analysis and discussion is paid to the connections between territorial governance arrangements on the one hand, and rural-urban interactions and synergies, cross-sectoral interaction and cooperation and socio-economic development, on the other hand. Related to this, we ask whether and how the relations between urban, peri-urban and rural areas are actually being considered in current territorial governance arrangements and in spatial planning.

Concerning the effectiveness of planning, we ask whether and at what stages civil society organisations play a role in the plan elaboration process. Finally, what further mechanisms are in place to ensure plan implementation, and what is the role of complementary policy tools?

We think that these research questions and the related analysis and discussion are in several respects important and timely: First, a more sustainable and territorially integrated development is becoming increasingly important in global, EU and national-level policy making. Second, there is ample scope for better information on good practice in spatial planning and planning and territorial governance among European countries and regions, and beyond. Third, we still need to better understand how an effective interplay between spatial planning and territorial governance can contribute to achieving a more sustainable development.

\section{Methodology and Empirical Basis}

\subsection{Methodology, Analytical Framework and Criteria}

The approach used for this analysis combines regional case studies with rapid appraisals, the analysis of published data, expert judgement and triangulation. The use of a regional case study approach ensures that the strategies, plans and governance processes identified in each of the regions are analysed with close attention paid to the unique mix of resources, structures, formal and informal institutions, aspirations and development trajectories that each region features. In line with this approach, we do not aim to compare across regions, but rather to look at territorial relations and governance using the lenses of integrated and participatory development. The diverse set of seven regions and plans allows us to examine and illustrate planning processes and governance arrangements in quite different circumstances. The cooperation between practitioners and specialists from the different countries in this analysis provides deep insights into how territorial relations are addressed in different national contexts.

The analytical framework presented in Table 2 draws out 12 criteria that-based on the reviewed literature-appear most effective in exploring the functioning of a more balanced 
and territorially integrated development planning. The criteria used in the analysis are grouped into the three broad dimensions: "Territorial relations and development"; "Civic engagement and planning process"; and "Coherence in territorial governance". It is recognised that some aspects, like "Collaborative governance and transparency" could also be understood as transversal, and therefore, equally relevant to any of the three dimensions.

Table 2. Key dimensions and aspects (criteria) of a more balanced and territorially integrated development planning.

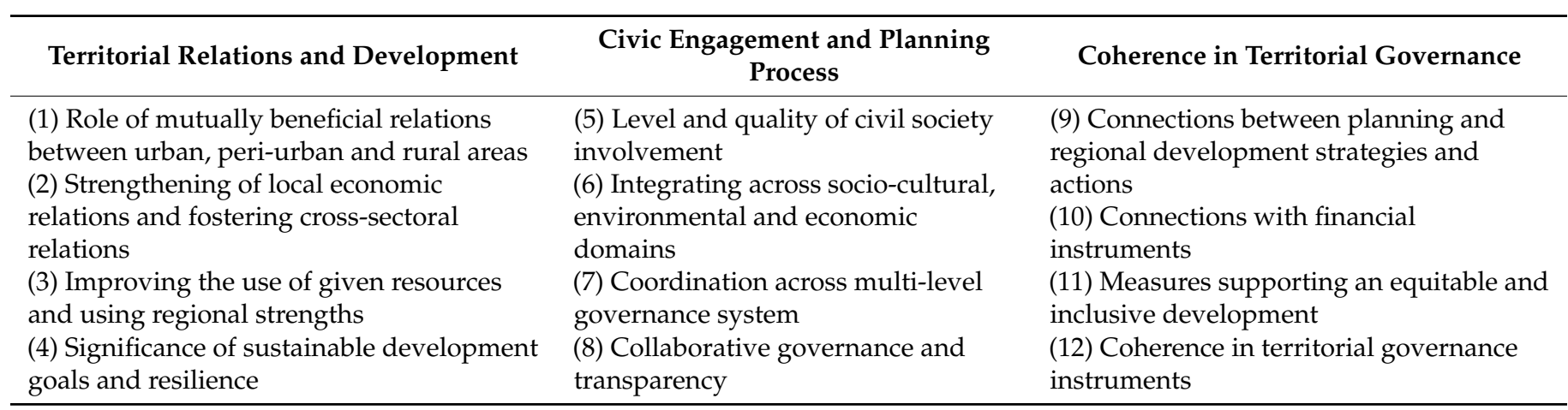

Source: Authors' compilation based on the results of the literature review.

The basic assumption underlying the empirical analysis presented in this article is that favourable manifestations in the dimensions of "Civic engagement in the planning process" and "Coherence in territorial governance" lead to a more balanced and territorially integrated development (represented by the dimension "Territorial relations and development"). Integrating across socio-cultural, environmental and economic domains (Criterion 6), for example, tends to contribute to an improved use of given resources and of regional strengths (Criterion 3), as well as sustainable development goals and resilience (Criterion 4). If in turn plans are linked with regional development strategies and actions (Criterion 9) and with financial instruments (Criterion 10), territorial development goals can be more effectively achieved. The simple examples illustrate that, what was described earlier as orchestration, plays a central role in the analysis and discussion.

\subsection{Empirical Basis}

The seven regional case studies that are the basis for the empirical analysis-Ede, Frankfurt/Rhein-Main, Styria/Graz, Helsinki, Lisbon, Lucca, Mid Wales-were carried out in the EU-funded Horizon 2020 ROBUST project which focusses on enhancing rural-urban relations [28] (see Figure 1).

The seven regions represent typical rural-urban settings in Europe. The cases were deliberately chosen to represent a broad spectrum of situations regarding jurisdiction, spatial and temporal scales, etc. to obtain a richer picture. At the same time, we recognise in each single case that scale differences and the interplay in a multi-level spatial planning system with differences in allocation of power and responsibilities matter. However, in this article we are more interested in the strengths and limitations of planning in a particular situation, i.e., at a given spatial and temporal scale, and in its respective connections with territorial development and programming.

Table 3 provides as background information a summary overview on the seven regions as well as a simple characterisation based on area size (sqkm), population density (inhabitants/sqkm) and population change (\% p.a.). The data indicate that there is one region with a low population density and significant depopulation (Mid Wales). Two regions have a very high population density and significant increases in population (Frankfurt/Rhein-Main, Lisbon). All other regions have a population density of around 200-400 inhabitants $/ \mathrm{km}^{2}$ and population changes of around $+1 \%$ p.a. Lucca stands out with an average population density and a slightly decreasing population. The plans that 
we refer to, and plan implementations, reflect these differences in challenges, opportunities and current goals.

Table 3. Brief characterisation of the seven regions.

\begin{tabular}{|c|c|c|c|c|}
\hline \multirow{2}{*}{ Region } & \multirow{2}{*}{$\begin{array}{l}\text { Area } \\
\mathrm{km}^{2}\end{array}$} & \multicolumn{2}{|c|}{ Population } & \multirow{2}{*}{ Central Challenge in Regional Development * } \\
\hline & & Density inh./sqkm & Change $* * \%$ & \\
\hline Ede, NL & 318 & 364 & $+0.9 \%$ & $\begin{array}{l}\text { Increased provision of ecosystem services, } \\
\text { diversification and territory-based cooperation }\end{array}$ \\
\hline $\begin{array}{l}\text { Frankfurt/Rhein- } \\
\text { Main, } \\
\text { DE }\end{array}$ & 2458 & 960 & $+1.2 \%$ & $\begin{array}{c}\text { Rebalancing economic and environmental goals, } \\
\text { increasing ecosystem services provision and quality } \\
\text { of life }\end{array}$ \\
\hline Helsinki, FI & 9568 & 176 & $+1.0 \%$ & $\begin{array}{l}\text { Achieving a balanced development of the larger } \\
\text { metropolitan region and strengthening of local } \\
\text { economic relations }\end{array}$ \\
\hline $\begin{array}{l}\text { Lisbon } \\
\text { Metropolitan } \\
\text { Area, PT }\end{array}$ & 3015 & 944 & $+1.3 \%$ & $\begin{array}{l}\text { Strengthening of local economic relations for a } \\
\text { harmonised and integrated territorial development }\end{array}$ \\
\hline $\begin{array}{l}\text { Lucca Province, } \\
\text { IT }\end{array}$ & 1773 & 220 & $-0.1 \%$ & $\begin{array}{c}\text { Valorising territory, landscape and cultural heritage, } \\
\text { and preserving social, environmental and cultural } \\
\text { values }\end{array}$ \\
\hline Mid-Wales, UK & 17,034 & 60 & $-0.2 \%$ & $\begin{array}{c}\text { Encouraging smart growth, maintaining landscapes, } \\
\text { natural resources, and the distinctive Welsh culture } \\
\text { and language }\end{array}$ \\
\hline $\begin{array}{l}\text { Metropolitan } \\
\text { Area of Styria, AT }\end{array}$ & 1890 & 261 & $+1.1 \%$ & $\begin{array}{l}\text { Fostering intercommunal cooperation in public } \\
\text { infrastructure, social services, new businesses and } \\
\text { cultural activities, enhancing quality of life }\end{array}$ \\
\hline
\end{tabular}

Source: Own compilation. * as expressed in regional development strategies, plans (and similar). ${ }^{* *}$ last 5 years in \% p.a.

The entry point into the analysis was a review of relevant studies, policy and strategy papers. One central element in the review was a rapid appraisal of a key spatial planning instrument currently or previously used in the respective case study region and considered important by regional experts.

The review and rapid appraisal of real-life examples of spatial planning, plans and plan implementation helped to better understand the status quo and to acquire information about the strategic frameworks used. All regional teams carrying out rapid appraisals were given detailed guidelines on how to carry out the rapid appraisals. The guidelines included checklists and a common reporting template to ensure the equivalence of the information gathered. We then sought complementary information in the form of published studies and statistics, as well as expert judgement, complementing the obtained information and checking its validity. The experts involved in data collection, joint reflection and triangulation are included as co-authors of this paper.

Table 4 provides an overview of the spatial planning instruments currently or previously used in the same case study regions. 


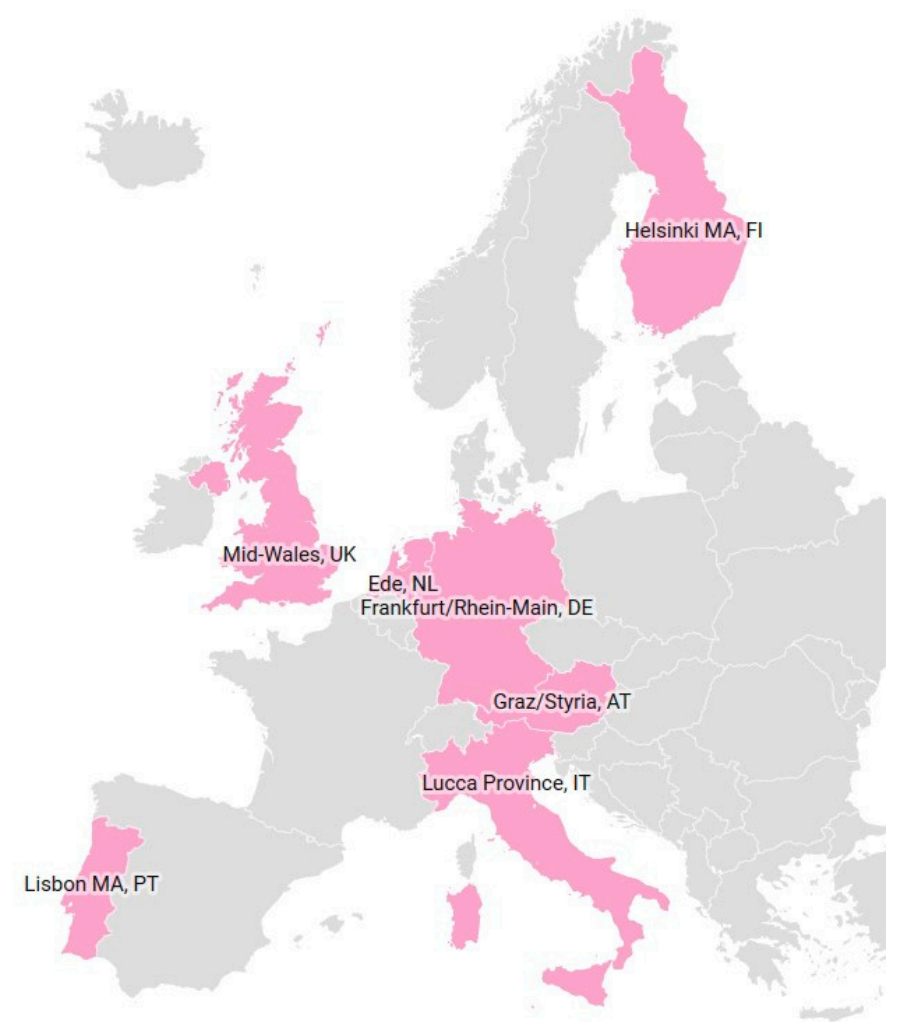

Figure 1. The seven study regions.

Table 4. Key spatial plans and laws in the case study regions.

\begin{tabular}{|c|c|c|c|c|}
\hline Name & Brief Description & Type * & Year & Ref. ** \\
\hline $\begin{array}{l}\text { Dutch Environment and Planning } \\
\text { Act and its implementation in Ede }\end{array}$ & $\begin{array}{l}\text { Aims to enhance the place-based integration of existing spatial } \\
\text { planning, environmental and nature-oriented regulatory } \\
\text { frameworks. }\end{array}$ & SP & 2016 & EDE4 \\
\hline $\begin{array}{l}\text { Regional Land Use Plan } \\
\text { Frankfurt/Rhein-Main and its } \\
\text { update }\end{array}$ & $\begin{array}{l}\text { A tailor-made modification of land use planning which covers } \\
\text { the area of } 75 \text { (from } 1 \text { April 2021: 80) municipalities and is } \\
\text { elaborated by the Regionalverband FrankfurtRheinMain. }\end{array}$ & LUP & 2010 & FRA1 \\
\hline $\begin{array}{l}\text { Law on Planning and } \\
\text { Development of the Province of } \\
\text { Styria and its regions }\end{array}$ & $\begin{array}{l}\text { The law defines the tasks of the province and of its seven } \\
\text { regions and the scope for intercommunal projects to be financed } \\
\text { by the regions. }\end{array}$ & $\mathrm{TP}$ & 2018 & GRA1 \\
\hline $\begin{array}{l}\text { Agreement on land use, housing } \\
\text { and transport in Helsinki region } \\
\text { (MAL) }\end{array}$ & $\begin{array}{l}\text { The } 14 \text { municipalities in Helsinki region cooperate in land use, } \\
\text { housing and transport. MAL describes the common intent, } \\
\text { including a shared land use plan and housing strategy. }\end{array}$ & $\mathrm{RP}$ & 2020 & HEL1 \\
\hline $\begin{array}{l}\text { Regional Spatial Plan for Territory } \\
\text { of Lisbon Metropolitan Area } \\
\text { (PROT-AML) }\end{array}$ & $\begin{array}{l}\text { The aim is to enable a coherent structuring of the Lisbon } \\
\text { Metropolitan territory. It is a strategic plan that is to achieve its } \\
\text { goals is by integrating norms into the Municipal Plans. }\end{array}$ & SP & 2002 & LIS2 \\
\hline $\begin{array}{l}\text { Law of Tuscany Region } 65 / 2014 \\
\text { and its implementation in Lucca } \\
\text { Province }\end{array}$ & $\begin{array}{l}\text { The aim is to enhance sustainable development, counteract land } \\
\text { consumption and promote the multifunctional role of the rural } \\
\text { territory. Public participation in drawing up the plans. }\end{array}$ & $\mathrm{TP}$ & 2014 & LUC1 \\
\hline $\begin{array}{l}\text { Wales Spatial Plan (WSP), now: } \\
\text { National Development } \\
\text { Framework (NDF) }{ }^{1}\end{array}$ & $\begin{array}{l}\text { Strategy for sustainable development with national spatial } \\
\text { priorities across key sectors, including health, education, } \\
\text { housing, economy, environmental and landscape management. }\end{array}$ & SP & 2008 & MWA1 \\
\hline
\end{tabular}

Source: Own compilation. * Type of planning (LUP = Land Use Planning; SP = Spatial Planning; RP = Regional Planning; TP = Territorial Planning). ${ }^{* *}$ Note: The reports mentioned in column "Ref." (e.g., EDE4) can be downloaded at: http:/ / rural-urban.eu/ (accessed on 28 April 2021). ${ }^{1}$ The WSP has meanwhile been replaced by the National Development Framework (NDF). 


\section{Analysis and Discussion}

The analysis and discussion follow the three research questions identified in Section 1.3:

- The role that the relations between urban, peri-urban and rural areas play in current territorial governance arrangements and in spatial planning.

- The role civic engagement plays for the outcomes of spatial planning.

- The mechanisms, processes and instruments that are in place to ensure plan implementation.

\subsection{The Roles That the Relations Between Urban, Peri-Urban and Rural Areas Play in Spatial Planning and in Current Territorial Governance Arrangements}

In the following discussion, we examine how much the creation of mutually beneficial relations between urban, peri-urban and rural areas is an explicit goal (Criterion 1); what are the aims of the strengthening of local economic relations and fostering of cross-sectoral relations (Criterion 2); how much improving the use of given resources and using regional strengths is an important consideration (Criterion 3); and what is the significance of sustainable development goals and resilience measures(Criterion 4).

Across the seven regions and plans, it is apparent that interests and goals differ significantly between urban, peri-urban and rural areas. Policymakers and planners tend to see cities as economic engines supported through agglomeration, creative capital and innovation, while the countryside is viewed as a place for food production, resource extraction and recreation. It is therefore not surprising that the related governance arrangements and planning processes involve trade-offs, and thus, deliberating and prioritisation. A topical example in several regional study areas (Ede, Frankfurt/Rhein-Main, Lucca) is the question of whether the further expansion of business areas in immediate proximity to urban cores is worth more than the maintenance of the capacity to produce food regionally and locally, or more than opportunities for recreation, high nature value areas and related qualities of life.

Scale differences matter in such assessments. Frankfurt/Rhein-Main, for instance, focusses on a meso-level administrative coordination of land use, including democratic control and accountability aspects, whereas Ede is much more focussed on incorporating social and economic development considerations and using participatory approaches to achieve that. In Italy, the municipal planning scale is the most incisive in terms of territorial transformations. Key questions in Lucca Province are how spatial planning can contribute to promoting multifunctional and sustainable agriculture and food systems in peri-urban areas, and how urban sprawl can be restricted, and thus, the environment and landscape protected [29]. The Regional Land Use Plan in Frankfurt/Rhein-Main also aims at conserving open space, but it covers a much larger area, representing a continuum from urban to rural with the majority being peri-urban. The Regionalverband adopts a broad view of spatial planning by defining the fostering of sustainable regional development as the overarching goal [30].

Irrespective of differences in scale, do we see evidence in the seven regional examples that current territorial governance arrangements and spatial planning pay particular attention to the interdependencies between urban, peri-urban and rural areas, and to fostering more beneficial territorial relations?

Conventional land use planning tends to focus on allocating alternative land uses (and thus activities, revenues, etc.) in a way that is perceived by public sector decisionmakers and planners as maximising benefits for an area [31]. Given and planned public infrastructure, like train lines and stops, is usually considered when allocating land uses, as well as factors like trends in population density and expected housing requirements. The Frankfurt/Rhein-Main case illustrates this well. The ongoing reform of the planning process aims at widening perspectives by also considering quality of life and sustainability goals, and making these goals more explicit in spatial planning [30].

The Helsinki region, Lisbon Metropolitan Area, Province of Lucca and Metropolitan Area of Styria/Graz cases highlight the objective of territorial integration across rural- 
urban boundaries. In Styria/Graz, the roles of the province and of the regions are explicitly defined by the Law on Planning and Development, which is meant to provide a sound basis for cooperation and innovative rural-urban interaction. The Metropolitan Area of Styria is characterised by a substantial rate of immigration, while the more rural parts of the region need to manage the demographic downturn of young and well-educated people and its related effects. A key instrument in fostering a more integrated territorial development is the regional development budget, which is drawn from provincial and municipal resources and allocated to intercommunal projects [32]. In contrast, the MAL agreement in Helsinki region focusses on developing city regions in an environmentally sustainable way. It does not explicitly address enhancing rural-urban interactions. At the same time, a key question for decision-makers in Helsinki and the more rural Uusimaa region is how to locally facilitate the creation of new joint planning practices [33]. Similarly, PROT-AML in Lisbon Metropolitan Area is the plan of a mainly urban area with guidelines that primarily focus on urban problems. Its rural dimension is mostly expressed in terms of controlling urban pressure and identifying important economic activities in rural areas [34].

Regarding an integrated urban-rural planning, the example of how some PROT-AML guidelines are implemented at the Municipal Master Plan level is helpful. One of the 17 territorial units of the planning region is the Northern Agricultural territory, with economically important agricultural activities. The pressures caused by the disorganised occupation of the territory by dispersed industrial developments and insufficiently planned growth of urban centres are jeopardizing the functioning of the territory, and specifically farming activities. Spatial planning, including in neighbouring territories, focusses on better concentrating the housing supply and space for economic activities in urban centres. At the same time, initiatives in specific tourism niches, including in rural areas, are promoted to achieve a more integrated development [34].

In Italy, in the 1970s, spatial planning became a competence of the regions and, therefore, each region issued its own law governing the territory. All these laws are inspired by an urban-centric vision. However, in some regions, principles that recognise the role of rural spaces for sustainable development were introduced. In the region of Tuscany, for example, the Urban Planning Law 65/2014 aims to enhance landscape heritage for sustainable development, counteract land consumption and promote the multifunctionality of the territory. Still, the abandonment of peri-urban agricultural areas is widespread, which is why Galli and Rovai (2018) argue that a new vision of territory is needed that can offer a higher quality of life and well-being. The same authors continue to argue that, from the spatial planning point of view, the law formally recognises the strategic role that rural territories have for sustainable development and enhanced relationships between the city and countryside. However, in practice, the related governance is limited to regulating building permissions [29]. Galli and Rovai (2018) conclude that the meanings and the potentials that agricultural activities could gain, in view of reciprocal and less-conflictual linkages with urban areas, are not sufficiently considered [29]. This resonates with Heley's analysis of the Wales Spatial Plan, which identifies the region's ecosystems as of primary importance to its social and economic fabric, while falling short in fostering development through agricultural innovation and tourism, protecting landscapes and enhancing their function in addressing the challenges of climate change [26].

In summary, there are few indications of a more balanced, sustainable and territorially integrated development be recognised. The creation of mutually beneficial relations between urban, peri-urban and rural areas (Criterion 1) and the strengthening of local economic relations and fostering of cross-sectoral relations (Criterion 2) are explicit goals in Ede, Lisbon and Lucca. In other regions, the relations between urban, peri-urban and rural areas play only indirect or implicit roles in spatial planning. Where this is the case, this is in conjunction with other planning goals such as containing urban expansion (as in Frankfurt/Main) or maintaining environmental and rural assets. The Ede example illustrates the potential, as well as the challenges, of downscaling rural-urban coordination. Generally, there are only limited indications of the aim to explicitly foster more benefi- 
cial relations between urban, peri-urban and rural areas through spatial planning. The findings are supported by comparable analyses by Harrison (2010) [35], Harrison and Heley (2015) [36] and Coombes (2013) [37]. Improving the use of given resources and using regional strengths is an important consideration (Criterion 3) in most regions, and the same applies to the significance of sustainable development goals and resilience (Criterion 4).

\subsection{The Role Civic Engagement Plays for the Outcomes of Spatial Planning}

In the following discussion, we explore how the nature of spatial planning and decision-making changes when citizens and private and non-profit sectors are involved. The related criteria are as follows: "Integrating across socio-cultural, environmental and economic domains" (Criterion 5), "Coordination across multi-level governance system" (Criterion 6), "Level and quality of civil society involvement" (Criterion 7) and "Collaborative governance and transparency" (Criterion 8).

Some regional examples illustrate in what ways civil society engagement can matter in planning processes and for planning outcomes. The Regionalverband Frankfurt/RheinMain's governing body, the Regionalvorstand (regional board) provides an example of a more formalised practise of civil society involvement. The 30 members of the regional board represent civil society in the form of trade unions, chamber of crafts, chamber of industry and commerce, etc. Some board members have an advisory role or guest status [30]. Equivalent evidence of new forms of governance and civil society involvement can also be in the Netherlands. The NEPA framework redistributes policy responsibilities between national, provincial and municipal administrations, thereby giving municipalities a more prominent role in integrating regulatory frameworks. The Ede municipality, for example, explores a more flexible, tailor-made NEPA implementation. A related goal is to increase stakeholder participation and involvement in policymaking [38].

In the impact assessment of the MAL agreement in Helsinki, the transparency of the planning process is considered particularly important. Key issues include the use of information in decision-making and the role of open discussions, also including residents [33].

Preparation of the PROT-AML in the Lisbon Metropolitan Area was supported by an advisory committee that includes members of national- and local-level public administrations representing territorial, environmental, economic, social and cultural interests [34]. Pina (2018) points out that those advisory committees which support plan preparation are led mostly by legal compliance, thus missing the opportunity to generate a truly reflective and strategic insight into plan development [34].

The Law of Tuscany Region 65/2014 includes public participation for drawing up the territorial plans. Citizens have the right of access to administrative documents related to territorial governance. Arcuri et al. (2018) point to the need to activate new kinds of relationships with civil society organisations and that sharing the related knowledge and experiences can help overcome limitations in planning [39]. Limiting factors are the technical language used by planners and the resistance of decision-makers to participatory processes [40].

Oversight and delivery of the Spatial Plan in Wales was in the hands of Area Groups that were established for each region and comprised representatives from the private, public and third sector. The role of these groups was to align institutional investments and provide a forum for collaborative planning within and across rural and urban contexts [26]. Table 5 provides a summary overview. 
Table 5. Levels and kinds of civil society engagement.

\begin{tabular}{|c|c|c|c|}
\hline Region & $\begin{array}{l}\text { Type of } \\
\text { Planning }\end{array}$ & $\begin{array}{l}\text { Level of CS } \\
\text { Involvement }\end{array}$ & $\begin{array}{l}\text { Kind and Role of } \\
\text { CS Involvement }\end{array}$ \\
\hline Dutch Environment and Planning Act, implementation in Ede & SP & medium & stakeholders \\
\hline Regional Land Use Plan Frankfurt/Rhein-Main & LUP & medium & representative \\
\hline $\begin{array}{c}\text { Law on Planning and Development of the Province of Styria and its } \\
\text { regions }\end{array}$ & $\mathrm{TP}$ & medium & stakeholders \\
\hline $\begin{array}{l}\text { Agreement on land use, housing and transport in Helsinki region } \\
\text { (MAL) }\end{array}$ & $\mathrm{RP}$ & medium & open discussions \\
\hline $\begin{array}{l}\text { Regional Spatial Plan for Territory of Lisbon Metropolitan Area } \\
\text { (PROT-AML) }\end{array}$ & $\mathrm{SP}$ & medium & $\begin{array}{l}\text { advisory } \\
\text { committee }\end{array}$ \\
\hline Law of Tuscany Region 65/2014, implementation in Lucca Province & $\mathrm{TP}$ & high & $\begin{array}{l}\text { citizens, } \\
\text { stakeholders }\end{array}$ \\
\hline Wales Spatial Plan, now National Development Framework (NDF) & SP & medium & representative \\
\hline
\end{tabular}

Source: Own compilation.

In summary, our examples suggest that participation and partnerships that link public, private and non-profit sectors still tend to play only a partial role in spatial planning processes. The reality of implementation might sometimes still be lagging. Integrating across socio-cultural, environmental and economic domains (Criterion 5) can be seen as a given in the different case studies. In respect to coordination across multi-level governance systems (Criterion 6), an increasing importance of the (micro-)regional and local level in the fine-tuning and implementation of policies and plans is clearly recognisable. Regarding the level and quality of civil society involvement (Criterion 7), it appears that environmental, agricultural and consumer groups, science, the church, unions and individual citizens could still contribute more to policy development, spatial planning and implementation, and not only within their specific spheres of influence. A more significant shift from top-down government to place-based approaches and civic engagement still remains to be seen. The main shortcoming that generally remains is the tendency to elaborate and discuss plans in expert committees and through institutional representation, which results in a limited realisation of collaborative governance and transparency (Criterion 8).

\subsection{The Mechanisms, Processes and Instruments That Are in Place to Ensure Plan Implementation}

In the following analysis and discussion, we apply the four criteria subsumed under the heading "Coherence in territorial governance" in the analytical framework: "Connections between planning and regional development strategies and actions" (Criterion 9), "Connections with financial instruments" (Criterion 10), "Measures supporting an equitable and inclusive development" (Criterion 11) and "Coherence in territorial governance instruments" (Criterion 12).

The Law of Tuscany Region 65/2014, Italy, provides a telling example of the mechanisms, processes and instruments in place to ensure plan implementation. As the law is essentially a planning tool, it is not really concerned with the modalities and instruments that are necessary to activate the planning. Galli and Rovai (2018) emphasise that integration with existing policies and the dedication of sufficient financial resources to this are needed. Pilot projects are perceived as a suitable strategy for fostering implementation of territorial plans and achieving goals [29]. At the same time, it seems clear from the case study that spatial planning alone is insufficient in achieving more specific goals like enhancing rural-urban relations. Boosting rural livelihoods can be achieved through the valorisation of local food, but this requires additional instruments [29].

Other regional case studies provide specific insights into the potentially highly effective interplay between different instruments and mechanisms: In Ede, the Netherlands, the need for complementary measures that foster implementation appears less pronounced, 
as those enacting the plan are directly involved in the plan establishment. Planning agencies seek to foster implementation and positive change by integrating municipal food, environmental and spatial planning policies. Joint goals are being formulated and indicators identified for monitoring changes in more holistic ways. The aim of new and more flexible spatial planning instruments that are currently being elaborated is to task rural entrepreneurs to improve their environmental and spatial quality performance in line with wider objectives. Business development plans which do not fit in existing regulations can be negotiated with municipal authorities [40]. In Ede, the initiator of a project that does not fit in existing regulatory frameworks must seek planning permission. The start for this is a dialogue not only between the private entrepreneur and local government, but also between the entrepreneur and other local stakeholders. The approach aims at mobilising micro-level private funding for certain societal gains. In Ede, investors are asked to benefit society in return for a planning permission [38].

In Frankfurt/Rhein-Main, Germany, individual municipalities are no longer free to determine the future use of land in their territories because their local plans (the standard legal requirement for planning permissions) must follow the Regional Land Use Plan, which is elaborated centrally. At the same time, all local government authorities within the Frankfurt/Rhein-Main agglomeration are encouraged to form networks to jointly tackle specific tasks. As a result, currently more than 20 groupings, associations or agencies are actively covering a broad portfolio of interests from public transport to pharmacy, from culture to universities, including private companies and the chambers of industry and commerce [30]. Integrating norms into the municipal plans in the Lisbon Metropolitan Area is also one of the ways to achieve the goals of strategic spatial planning. The Regional Land Use Programmes are to integrate national-level development priorities with sub-regional and local goals and strategies. The problem is that, so far, only 9 of the 18 municipalities implemented this approach, despite the strategic plan having been in force for 16 years. Pina (2018) argues that this delay is caused, on the one hand, by frequent changes in priorities and legislation at the national level and, on the other hand, by uncertainties that arise when concrete decisions about priorities need to be made. Other reasons include the lack of incentives, and the fact that the law had approved the plan did not impose a deadline for its transposition to the Municipal Master Plans [34].

In the Metropolitan Area of Styria/Graz, the autonomous use of the financial resources that is enacted with the Law on Planning and Development clearly goes beyond spatial planning. It also includes provisions for regional development budgets and, for example, for more specific financial incentives for encouraging intercommunal cooperation. Bauchinger (2018) argues that such incentives are crucial not only in stimulating cooperative strategies, but also for considering the overall development of the Styrian regions, instead of continuing separate action. In this context, intercommunal cooperation is the main precondition to receive financial support for projects from the regional development budget. The law enhances the autonomy of regions, which in turn fosters the adaptation of measures to local needs, challenges and potentials [32]. The Helsinki region pursues similar strategies to execute the MAL agreement and related planning. While the cooperation of the city and its neighbouring municipalities in transport, housing and land use plans is in the centre, the cooperation is supported by the State with financial incentives. This support includes major investments in rail transport, cycling routes and public transport [33].

One significant lesson from these different cases is that spatial planning must clearly, as Beattie (2010) put it, go beyond "jumbling simply everybody's ideal sector-based outcomes together" [35] (p. 14). Instead, the focus needs to be on addressing societal needs and aspirations, as well as on guidelines that are deliverable and that will, as a result, be implemented. Beattie (2010) adds that planners need to move well beyond the rhetoric of integration, and that spatial planning must become a way of working to solve problems across organisations [41].

The example of Lisbon suggests that continuity in higher-level frameworks, as well as in legally binding time schedules and agreements, is also important [29]. In the implemen- 
tation of the Stadt-Land-Partnerschaften in Germany, the legal, financial and infrastructural conditions were found to be central for achieving goals [24,25]. The Styria/Graz example reinforces the important role of funding and of suitable funding mechanisms in realising (spatial) plan outcomes. In this respect, Beattie (2010) warns that there is a risk that spatial planning activities might relapse into infrastructure programmes, and that regional preferences might simply be too different to central government's (infrastructure) preferences [41].

Summing our arguments regarding coherence in territorial governance, we would emphasise how important it is that spatial planning tools are complemented by mechanisms and instruments that ensure effective implementation. Connections between planning and regional development strategies and actions (Criterion 9) play a central role in most regions, especially in Ede, Styria and Lucca. So far, only limited use has been made of connections with financial instruments (Criterion 10). Styria and Helsinki illustrate this approach. Measures supporting an equitable and inclusive development (Criterion 11) do not seem to play a significant role in the seven regions. Ede, Styria and Lisbon provide vivid illustrations of coherence in territorial governance instruments (Criterion 12). Our examples also show that context plays an important role: To try and overcome the limitations of high-density regulatory frameworks is an obvious goal in the Netherlands, where regulation and collective management are hugely important, while it might be much less important elsewhere. The active search for mutual benefits, like in the Ede and Lucca cases, between spatial planning tools and local food policy is an effective strategy for fostering the implementation of territorial plans. These findings are supported by research from Rodríguez-Pose (2009), who points to the trend towards place-based strategies [42], as well as Woods (2009), who refers to the need to make connections [43].

\subsection{A Synopsis of Key Findings}

Table 6 provides a synopsis of the functioning of a more balanced and territorially integrated development planning in the seven case study regions. Criterion marked " $\mathrm{h}$ " (high) indicate regions where a particular factor is very favourable, and " $\mathrm{m}$ " (moderate) denotes regions where a factor is somewhat favourable. Empty cells denote that a criterion does not play a significant role. The scoring is based on the information and examples provided in the previous sections and the best professional judgement of the author(s) from the respective region.

Related to "Territorial relations and development" (Dimension 1), two criteria stand out across the seven case study regions as playing a significant role: (1) "Improving the use of given resources and using regional strengths" (Criterion 3) and (2) "Significance of sustainable development goals and resilience" (Criterion 4). Based on all four criteria, Lucca, Lisbon and Ede, stand out. The relations between urban, peri-urban and rural areas are only explicitly considered in four out of the seven spatial plans.

Dimension 2 "Civic engagement and planning process" appears more favourable in Lucca and Styria. "Level and quality of civil society involvement" (Criterion 5) is favourable in six out of the seven regions. The intention of "Integrating across sociocultural, environmental and economic domains" (Criterion 5) is important in five regions.

Related to "Coherence in territorial governance" (Dimension 3), the only criterion that can be seen as (very) favourable in most of the case study regions is "Connections between planning and regional development strategies and actions " (Criterion 9). "Coherence in territorial governance instruments" (Criterion 12) is favourable in Styria, and somewhat less in Ede, Lisbon and Lucca. In consideration of all four criteria, only Styria stands out in respect of the coherence in territorial governance.

Based on our seven case studies we can, as initially hypothesised, recognise connections between "Civic engagement and planning process", "Coherence in territorial governance" and "Territorial relations and development". These, in terms of planning outcomes and important connections, are most clearly recognisable in Styria, Lucca and Ede. Overall, it can be seen that more beneficial territorial relations need more than (spa- 
tial) planning, and that complementary territorial governance arrangements are needed. However, a larger number of in-depth case studies is needed to establish these relations more firmly. The empirical analysis presented here is, as emphasised earlier, exploratory.

Table 6. Summary overview on how favourable different planning aspects are in each plan and region in terms of achieving more balanced and territorially integrated development (" $h$ " = high; "m" = moderate; empty cells denote that a criterion does not play a significant role).

\begin{tabular}{|c|c|c|c|c|c|c|c|c|c|c|c|c|}
\hline \multirow{2}{*}{ Case Study Plan } & \multicolumn{4}{|c|}{$\begin{array}{c}\text { Territorial Relations and } \\
\text { Development }\end{array}$} & \multicolumn{4}{|c|}{$\begin{array}{l}\text { Civic Engagement and } \\
\text { Planning Process }\end{array}$} & \multicolumn{4}{|c|}{$\begin{array}{c}\text { Coherence in Territorial } \\
\text { Governance }\end{array}$} \\
\hline & 1 & 2 & 3 & 4 & 5 & 6 & 7 & 8 & 9 & 10 & 11 & 12 \\
\hline $\begin{array}{l}\text { Dutch Environment and Planning Act } \\
\text { and its implementation in Ede }\end{array}$ & $\mathrm{m}$ & $\mathrm{m}$ & $\mathrm{m}$ & $\mathrm{m}$ & $\mathrm{m}$ & & $\mathbf{h}$ & $\mathbf{h}$ & $\mathbf{h}$ & & & $\mathrm{m}$ \\
\hline $\begin{array}{l}\text { Regional Land Use Plan } \\
\text { Frankfurt/Rhein-Main }\end{array}$ & $\mathrm{m}$ & & $\mathbf{h}$ & $\mathrm{m}$ & $\mathrm{m}$ & $\mathbf{h}$ & $\mathrm{m}$ & & & & & \\
\hline $\begin{array}{l}\text { Law on Planning and Development, } \\
\text { Province of Styria and its regions }\end{array}$ & & $\mathrm{m}$ & $\mathrm{m}$ & $\mathrm{m}$ & $\mathbf{h}$ & $\mathrm{m}$ & $\mathrm{m}$ & $\mathrm{m}$ & $\mathbf{h}$ & h & & h \\
\hline $\begin{array}{l}\text { Agreement on land use, housing and } \\
\text { transport in Helsinki region }\end{array}$ & & & $\mathrm{m}$ & $\mathrm{m}$ & & $\mathrm{m}$ & & $\mathrm{m}$ & $\mathbf{h}$ & h & & \\
\hline $\begin{array}{c}\text { Regional Spatial Plan for Territory of } \\
\text { Lisbon Metropolitan Area }\end{array}$ & $\mathrm{m}$ & $\mathrm{m}$ & $\mathrm{m}$ & $\mathbf{h}$ & $\mathrm{m}$ & $\mathrm{m}$ & & & $\mathrm{m}$ & & & $\mathrm{m}$ \\
\hline $\begin{array}{l}\text { Law of Tuscany Region 65/2014, } \\
\text { implementation in Lucca Province }\end{array}$ & $\mathrm{m}$ & $\mathrm{m}$ & h & $\mathrm{m}$ & $\mathrm{m}$ & $\mathrm{m}$ & $\mathbf{h}$ & $\mathrm{m}$ & $\mathbf{h}$ & & & $\mathrm{m}$ \\
\hline $\begin{array}{l}\text { Wales Spatial Plan, now National } \\
\text { Development Framework (NDF) }\end{array}$ & & & $\mathrm{m}$ & $\mathrm{m}$ & $\mathrm{m}$ & & & & $\mathrm{m}$ & & & \\
\hline
\end{tabular}

1: Role of mutually beneficial relations between urban, peri-urban and rural areas. 2: Strengthening of local economic relations and fostering cross-sectoral relations. 3: Improving the use of given resources and using regional strengths. 4: Significance of sustainable development goals and resilience. 5: Level and quality of civil society involvement. 6: Integrating across socio-cultural, environmental and economic domains. 7: Coordination across multi-level governance system. 8: Collaborative governance and transparency. 9: Connections between planning and regional development strategies and actions. 10: Connections with financial instruments. 11: Measures supporting an equitable and inclusive development. 12: Coherence in territorial governance instruments.

\section{Conclusions}

The analysis presented in this article is exploratory. The assessment and following conclusions are therefore only indicative. Yet, overall, we found numerous signs of a shift towards a more balanced, sustainable and territorially integrated development.

At the same time, we found that the relations between urban, peri-urban and rural areas play only an indirect role in current territorial governance arrangements and spatial planning. While great care needs be taken not to overly simplify or generalise regarding the strengths of spatial planning approaches and their limitations, there persists a tendency that rural and urban areas are treated separately in policy and planning.

Where spatial planning cuts across territorial boundaries, new opportunities emerge that show how cities can in many respects benefit from the countryside, and vice versa. Participatory and integrative planning methods, new forms of vertical coordination and an increased use of bottom-up approaches play a central role in this, as well as stimulating private investments in public goods. Coordination across policy domains can also foster the cooperation between economic sectors and public-private collaboration. Often, and increasingly, this is an explicit goal. Several examples indicate how important the bigger picture is and that plans need to provide a long-term vision while leaving enough space for shorter-term actions. Achieving both is not easy. Integrated decision-making and consensus for larger territories can mean that plans and development strategies are too general to provide a practical base to build upon in many localities.

Does the role civil society and its organisations play in spatial planning matter for outcomes? On the basis of our analysis, we conclude that spatial planning needs to above all integrate different goals and interests. Planning is in this respect as much a social process 
as a technical one. If we follow this line of argument, it seems clear that spatial planning needs to combine the expertise from different professions and be based on a recognition of the value of different perspectives. All of this is not easy. Above all, it requires a culture change and a skill set that can only be cultivated over time. Our examples also indicate that current institutional arrangements are not always conducive to participation, integration and private sector engagement. Instead, there are indications that participatory elements are sometimes mainly used to legitimise plans and decisions.

What mechanisms, processes and instruments are in place to ensure plan implementation? Our regional examples indicate that the ability of spatial planning instruments to produce a desired result, and their contribution to higher-level strategies, are limited by ineffective (or toothless) implementation. All seven regions studied show that achieving more beneficial relations between urban, peri-urban and rural relations needs more than planning. Spatial planning plays an important role in coordinating different interests, but it needs to be accompanied by strategic frameworks and instruments that warrant implementation. The implementation gap is, at least partly, due to insufficient linkages between spatial planning, policy development and implementation. The challenge is therefore to get the right balance and interplay of institutions, actors and instruments across scales.

Several mechanisms were identified that can promote an effective and successful implementation: Integrated planning approaches and operational flexibility in planning arrangements help to deal with today's complex policy and planning environment. Plans that meet broad societal needs and aspirations, and that are deliverable, have a much better chance of being implemented. An appropriate extent of civil society engagement in spatial planning supports integrating different goals and interests, and prioritising. More participatory planning procedures can also increase the possibilities for addressing environmental and social goals. The kind of stakeholder involvement depends considerably on given legal frameworks and planning mandates. Facilitating private sector initiatives that fit in a broader development view is another key feature of more advanced planning concepts.

Municipalities might pursue strategies that are not completely in line with regionallevel visions. However, they might be willing to support higher-level rural-urban strategies if these plans and strategies are (at least partially) beneficial for the local level as well. Fiscal regimes and novel ways of compensation can play a key role in this.

The experience gained from our seven case studies indicates that the general trend towards framework steering, and towards territorially and place-based measures, can contribute to improving the relations between rural, peri-urban and urban areas. The challenge that remains is achieving greater integration of sectoral policies which, currently, often produce incoherent effects. The measures to be implemented in the context of the European Green Deal [44], and the strategic plans to be drawn up by member states under the post-2020 Common Agricultural Policy [45] could become useful new pieces in the puzzle. The prerequisite is that spatial planning and territorial governance processes are open and aligned with each other.

To conclude, we would like to emphasise that the questions we addressed in this article in an exploratory fashion merit further research. A more sustainable and territorially integrated approach to development is becoming increasingly important in global, EU and national-level policy making. We therefore need to gain a much better understanding of the interplay between different types of spatial planning, territorial governance and different forms of civic engagement. One key question that should be followed up in further research is the role of financial incentives, including through fiscal arrangements and targeted investments. The potential of the approach used in Ede is to simultaneously foster participation at the micro-level while achieving public goals through private sector investments. The example suggests that, until now, there has clearly been too little experimentation with more collaborative models of organisation, planning and decision-making, as well as different forms of civic engagement. The importance of the interplay between different governance levels and the coordination across territorial and sectoral boundaries 
are findings of our research that are in line with earlier studies $[40,46]$. These findings merit further research, especially in respect of fostering a more sustainable development.

Author Contributions: Conceptualization, K.K.; methodology, K.K.; analysis, All authors; investigation, All authors; writing—original draft preparation, K.K.; writing—review and editing, All authors. All authors have read and agreed to the published version of the manuscript.

Funding: This research is funded by the ROBUST project, as part of the Horizon 2020 Framework Programme of the European Union under Grant Agreement no. 727988. The information and views set out in this article are those of the author(s) and do not necessarily reflect the official opinion of the European Union.

Institutional Review Board Statement: Not applicable.

Informed Consent Statement: Not applicable.

Data Availability Statement: Data sharing not applicable.

Acknowledgments: The authors would like to thank all colleagues in the ROBUST project and Alexia Rouby of DG AGRI, European Commission.

Conflicts of Interest: The authors declare no conflict of interest. The funders had no role in the design of the study; in the collection, analyses, or interpretation of data; in the writing of the manuscript, or in the decision to publish the results.

\section{References}

1. Romeo, L. What is territorial development? GREAT Insights Mag. 2015, 4, 15-17.

2. Bernstein, S.; van der Ven, H. Best practices in global governance. Rev. Int. Stud. 2017, 43, 534-556. [CrossRef]

3. UN Habitat. International Guidelines on Urban and Territorial Planning, towards a Compendium of Inspiring Practices; United Nations Human Settlements Programme (UN-Habitat): Nairobi, Kenya, 2015.

4. Allmendinger, P. Planning Theory; Palgrave Macmillan: London, UK, 2009.

5. Shucksmith, M. Disintegrated Rural Development? Neo-endogenous Rural Development, Planning and Place-Shaping in Diffused Power Contexts. Sociol. Rural. 2010, 50, 1-14. [CrossRef]

6. Naldi, L.; Nilsson, P.; Westlund, H.; Wixe, S. What is smart rural development? J. Rural. Stud. 2015, 40, 90-101. [CrossRef]

7. Nachhaltigkeitsrat. Perspectives for Germany, Our Strategy for Sustainable Development. 2005. Available online: http://www. nachhaltigkeitsrat.de/service/download/publikationen/broschueren/Broschuere_Nachhaltigkeit_und_Gesellschaft.pdf (accessed on 3 October 2020).

8. Fürst, D. Regional governance-ein neues Paradigma der Regionalwissenschaften? Raumforsch. Raumordn. 2001, 59, 370-380. [CrossRef]

9. Knickel, K. New divisions of responsibilities in rural areas, nature management and environmental education, Some relevant experiences in Germany. Essay prepared for the National Council of Rural Affairs in The Netherlands. 2005; Unpublished.

10. Healey, P.; Booher, D.E.; Torfing, J.; Sørensen, E.; Ng, M.K.; Peterson, P.; Albrechts, L. Civic Engagement, Spatial Planning and Democracy as a Way of Life Civic Engagement and the Quality of Urban Places Enhancing Effective and Democratic Governance through Empowered Participation, Some Critical Reflections One Humble Journey towards Planning for a More Sustainable Hong Kong, A Need to Institutionalise Civic Engagement Civic Engagement and Urban Reform in Brazil Setting the Scene. Plan. Theory Pr. 2008, 9, 379-414. [CrossRef]

11. Bertrand, N.; Kreibich, V. (Eds.) Europe's City-Regions Competitiveness, Growth Regulation and Periurban Land Management; Von Gorcum: Assen, The Netherlands, 2006.

12. Busck, A.G.; Hidding, M.C.; Kristensen, S.B.P.; Persson, C.; Præstholm, S. Planning approaches for rurban areas, Case studies from Denmark, Sweden and the Netherlands. Geogr. Tidsskr. J. Geogr. 2009, 109, 15-32. [CrossRef]

13. Briquel, V.; Collicard, J.J. Diversity in the rural hinterlands of European cities. In The City's Hinter-Land, Dynamism and Divergence in Europe's Periurban Territories; Hoggart, K., Ed.; Ashgate: Aldershot, UK, 2005; pp. 19-40.

14. Healey, P. The Treatment of Space and Place in the New Strategic Spatial Planning in Europe. Int. J. Urban Reg. Res. 2004, 28, 45-67. [CrossRef]

15. Smart Specialisation Strategy (S3) Platform. Available online: https://s3platform.jrc.ec.europa.eu/ (accessed on 3 October 2020).

16. Allmendinger, P.; Haughton, G. The Fluid Scales and Scope of UK Spatial Planning. Environ. Plan. A Econ. Space 2007, 39, 1478-1496. [CrossRef]

17. Boelens. Compacte Stad Extended, Agenda voor toekomstig belied, onderzoek en ontwertp. In Compact City Extended, Outline for Future Policy, Research and Design; Uitgeverj 010: Rotterdam, The Netherlands, 2011.

18. Busck, A.G.; Hidding, M.C.; Kristensen, S.B.P.; Persson, C.; Præstholm, S. Managing rurban landscapes in the Netherlands, Denmark and Sweden: Comparing planning systems and instruments in three different contexts. Dan. J. Geogr. 2008, $108,1-16$. 
19. Murdoch, J.; Marsden, T.K. Reconstituting Rurality, the Changing Countryside in an Urban Context; UCL Press: London, UK, 1994; p. 272.

20. Gallent, N.; Juntti, M.; Kidd, S.; Shaw, D. Introduction to Rural Planning; Routledge India: New Delhi, India, 2008.

21. Haughton, G.; Allmendinger, P.; Counsell, D.; Vigar, G. The New Spatial Planning, Territorial Management with Soft Spaces and Fuzzy Boundaries; Routledge: London, UK, 2010.

22. ESPON. Comparative Analysis of Territorial Governance and Spatial Planning Systems in Europe. Available online: https: //www.espon.eu/planning-systems (accessed on 3 October 2020).

23. Brown, D.L.; Shucksmith, M. Reconsidering territorial governance to account for enhanced rural-urban interdependence in America. Ann. Am. Acad. Political Soc. Sci. 2017, 672, 282-301.

24. BMVBS. Stadt-Land-Partnerschaften-Wachstum und Innovation Durch Kooperation; Bundesministerium für Verkehr, Bau und Stadtentwicklung: Bonn, Germany, 2012.

25. Obersteg, A.; Knieling, J.; Jacuniak-Suda, M. Urban-rural partnerships in metropolitan areas (and beyond). In Mobilising Regions, Territorial Strategies for Growth; Region-al Studies Association: London, UK, 2013.

26. Heley, J. Wales Spatial Plan. Rapid Appraisal Report, Rural-Urban Governance Arrangements and Planning Instruments; Aberystwyth University: Aberystwyth, UK, 2018.

27. Heley, J. Soft Spaces, Fuzzy Boundaries and Spatial Governance in Post-devolution Wales. Int. J. Urban Reg. Res. 2012, 37, 1325-1348. [CrossRef]

28. ROBUST-Unlocking Rural-Urban Synergies, EU Horizon 2020. Available online: http:/ / rural-urban.eu/ (accessed on 3 October 2020).

29. Galli, F.; Rovai, M. Law of Tuscany Region 65/2014 on the Government of the Territory. Rapid Appraisal Report, Rural-Urban Governance Arrangements and Planning Instruments, DAFE; University of Pisa: Pisa, Italy, 2018.

30. Henke, R. Regional Land Use Plan. Rapid Appraisal Report, Rural-Urban Governance Arrangements and Planning Instruments; Frankfurt/Rhein-Main, Germany, 2018; Unpublished project paper.

31. IPCC. Land Use, Land Use Change and Forestry; Cambridge University Press: Cambridge, UK, 2000.

32. Bauchinger, L. Law on Planning and Development of the Province of Styria and its Regions. Rapid Appraisal Report, Rural-Urban Governance Arrangements and Planning Instruments, Metropolitan Area of Styria; Austria/Federal Institute of Agricultural Economics, Rural and Mountain Research: Vienna, Austria, 2018.

33. Lahdelma, T. MAL Agreement, Regional Cooperation on Land Use, Housing and Transport. Rapid Appraisal Report, Rural-Urban Governance Arrangements and Planning Instruments; Helsinki, Finland, 2018; Unpublished project paper.

34. Pina, C. Regional Spatial Plan for the Territory of the Lisbon Metropolitan Area (PROT-AML). Rapid Appraisal Report, Rural-Urban Governance Arrangements and Planning Instruments; CCDR-LVT: Lisbon, Portugal, 2018.

35. Harrison, J. Networks of connectivity, territorial fragmentation, uneven development, the new politics of city-regionalism. Political Geogr. 2010, 29, 17-27. [CrossRef]

36. Harrison, J.; Heley, J. Governing beyond the metropolis, placing the rural in city-region development. Urban Stud. 2014, 52, 1113-1133. [CrossRef]

37. Coombes, M. From City-region Concept to Boundaries for Governance, The English Case. Urban Stud. 2014, 51, 2426-2443. [CrossRef]

38. Oostindie, H. Netherlands Environment and Planning Act (NEPA). Rapid Appraisal Report, Rural-Urban Governance Arrangements and Planning Instruments; Ede, The Netherlands, 2018; Unpublished project paper.

39. Arcuri, S.; Galli, F.; Rovai, M. Community for Food and Agro-Biodiversity. Rapid Appraisal Report, Rural-Urban Governance Arrangements and Planning Instruments, DAFE; University of Pisa: Pisa, Italy, 2018.

40. Nadin, V. The state of spatial planning systems in Europe and their capacity to meet the challenges of intense urban and regional flows. In Proceedings of the Warsaw Regional Forum, Warsaw, Poland, 18-20 October 2017.

41. Beattie, L. Spatial Planning and Urban-Implementation Challenges; School of Architecture and Planning, The University of Auckland: Auckland, New Zealand, 2010.

42. Rodríguez-Pose, A. Are city-regions the answer? In The Future of Regional Policy, 50-59; Tomaney, J., Ed.; Regional Studies Association/Smith Institute: London, UK, 2009.

43. Woods, M. Rural geography, blurring boundaries and making connections. Prog. Hum. Geogr. 2009, 33, 849-858. [CrossRef]

44. European Commission. A European Green Deal, Striving to Be the First Climate-Neutral Continent. 2020. Available online: https: / / ec.europa.eu/info/strategy / priorities-2019-2024/european-green-deal_en (accessed on 3 October 2020).

45. European Commission. Future of the Common Agricultural Policy. 2020. Available online: https:/ / ec.europa.eu/info/foodfarming-fisheries / key-policies / common-agricultural-policy/future-cap_en (accessed on 3 October 2020).

46. Peters, B.G. The challenge of policy coordination. Policy Des. Pr. 2018, 1, 1-11. [CrossRef] 